\title{
Two Bats in the Seychelles
}

\author{
P.A. Racey
}

Counts of the two endemic bats in the Seychelles in 1977 suggested that the fruit bat Pteropus seychellensis occurred in large numbers on Praslin and La Digue. But the author suggests that the number taken for food, especially for the tourist restaurants on Mahé, is excessive and should be curbed; tree-felling in suitable roosting areas should also be discouraged. The other bat, the small insectivorous Coleura seychellensis, is clearly endangered - only six were found despite an extensive search - and complete protection is called for.

The only endemic mammals in the Seychelles Islands are two bats: a fruit bat Pteropus seychellensis seychellensis and the small insectivorous Coleura seychellensis. The genus Pteropus includes the world's largest known bats, and extends from the Southern Pacific through Australasia and South-east Asia to the islands of the Indian Ocean. Because it occurs as far west as the islands of Pemba and $\mathrm{Mafia}$ but never reaches the African mainland 5 it has aroused the interest of zoogeographers. Hill recently examined the taxonomy of the rufus group of Pteropus, which occurs in the Malagasy region, and reduced the number of species to four. ${ }^{4}$ In doing so, he confirmed the validity of P.s. seychellensis.

Another species of Pteropus is the Indian Ocean fruit bat $P$. rodricensis, of which Cheke could count only 70 in September 1974 on Rodrigues; he presumed it to be the rarest bat in the world. In April and May 1976, Durrell estimated that the colony had increased to 120-130 individuals, but, since a single cyclone could destroy both roost and bats, 25 were caught and captive colonies established in Mauritius and Jersey. 1

In 1977 the second Aberdeen University expedition to the Seychelles decided to investigate the status of the two endemic mammals in the islands. We spent seven weeks in July and August on Praslin, the second largest island (39 sq km), where we made most of the fruit-bat observations reported here. We also paid short visits to the adjacent islands of Ia Digue (10 sq km) and Curieuse (4 sq $\mathrm{km}$ ), and to Mahé, the main island (109 sq km). On Praslin we spent about 10

BAT ROOSTS

A: La Pasquière

B: Fond Azore

C: Au Morne

D: La Digue

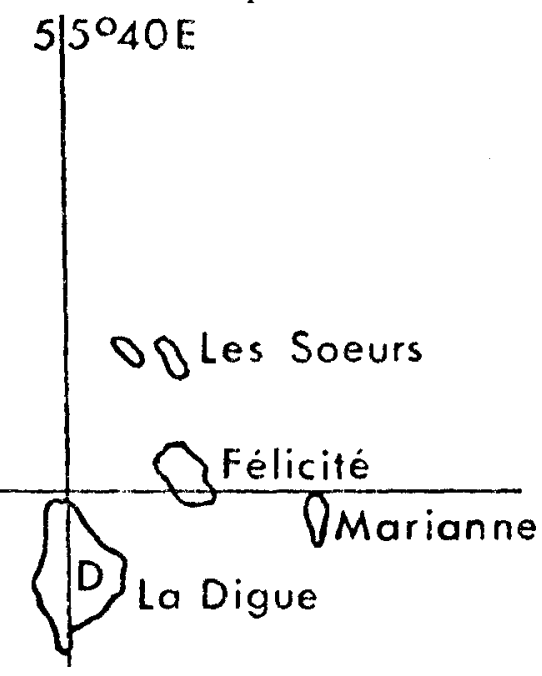



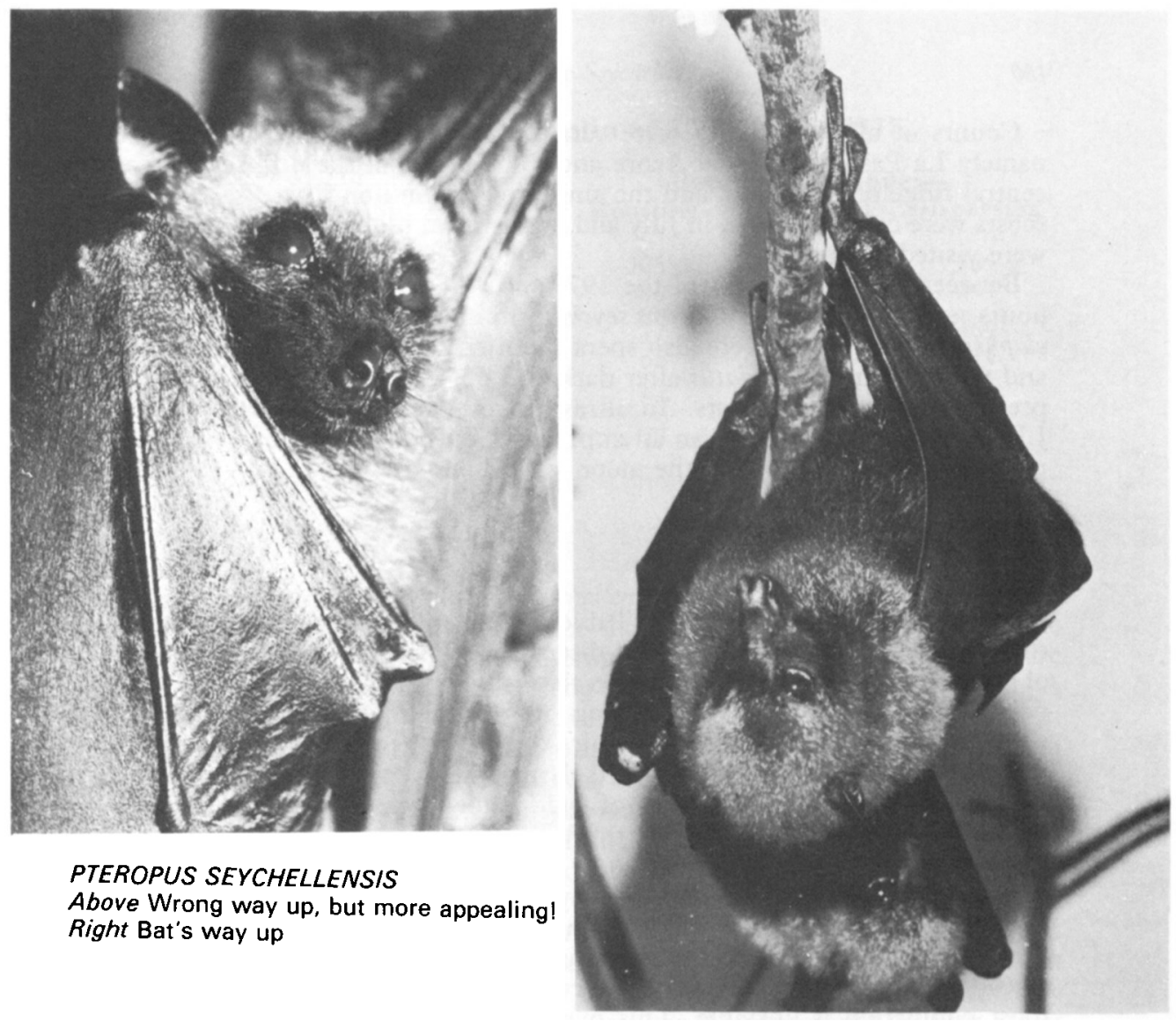

PTEROPUS SEYCHELLENS/S

Above Wrong way up, but more appealing! Right Bat's way up

days checking all possible roost sites of P.s. seychellensis and examined all the favoured roosting trees, Casuarina equisetifolia and Albizia falcata, that were sheltered from the prevailing south-east trade winds. But our searches failed to increase the number of roosts from the three known to the previous year's expedition from Aberdeen.

We carried out three types of counts:

1. Roost counts. Observers stationed at vantage points counted day-roosting bats, using binoculars and hand tally counters. Because the roosts could only be viewed from one direction, many bats were obscured by trees and these counts are considerable underestimates.

2. Disturbance counts. Two people approached the roosts stealthily and then, at a prearranged time, made as much noise as possible. The bats flying up from the roost were then photographed from a vantage point, using a wide-angle lens, and counted when the transparencies were projected on to a large screen. This method also produces underestimates if some bats do not react to the disturbance but remain in the roost.

3. Evening dispersal counts. Each roost was surrounded at some distance by at least four people, positioned to achieve the minimum of overlap. Each observer counted the bats as they left the roost to forage at dusk, and noted the direction taken by the bats. 
Counts of all three types were carried out on the three roosts on Praslin, namely I a Pasquière, Fond Azore and Au Morne, on the diffuse roost on the central ridge of I a Digue, and the single roost found on Curieuse. On Praslin, roosts were counted twice, in July and August, and both Curieuse and I,a Digue were visited twice.

Between them, members of the 1976 and 1977 expeditions spent about 100 hours searching caves for Coleura seychellensis and swiftlets Aerodramus francicus elaphrus. Many hours were also spent counting fruit bats and swiftlets at dusk and tenrecs Teurec ecaudatus after dark, and observers were asked to record the presence of small flying bats. An ultrasonic receiver, kindly loaned by Professor J.D. Pye, was also used in an attempt to detect the presence of flying Coleura, particularly on nights when the moon was obscured by cloud.

\section{Results}

The results are presented in the Table. Predictably, the counts of fruit bats at roost were always lower than either disturbance or dispersal counts. The success of roost counts obviously depends on the visibility of the roost from the vantage point. Visibility was very good looking across to the roost at I a Pasquière from a vantage point to the north (the Casimir ridge), and the number of bats counted at this roost approached those counted during the evening dispersal. Conversely the counts at Fond Azore were of little value because very few of the bats roosting there could be seen from the Vallee de Mai viewing lodge on the transisland road.

At La Pasquière and Fond Azore, evening dispersal counts proved to be the most satisfactory method of assessing numbers. Although there was good agreement between July and August dispersal counts at I a Pasquière, there was considerable disparity between these counts at Fond Azore, suggesting that the roost population is unstable. This may be explained by bats moving between roosts or between adjacent islands; we frequently saw them flying between Praslin and Cousin, for example. Disturbance counts were unsuccessful at these roosts because the vantage points were so far distant (about one $\mathrm{km}$ ) that the bats were not sufficiently magnified on the projected transparencies to be clearly distinguishable.

At the Au Morne roost the disturbance count was very successful because the photographer could approach to within 300 metres, while the disturbers climbed a promontory behind the roost and had the advantage of surprise when they came over the ridge shouting loudly. Photographs were taken sequentially throughout the disturbance and the flying bats counted on the projected transparencies. Dispersal counts, however, were unsuccessful at this roost becaue most of the bats travelled such a short distance before they alighted to feed that they were not clearly silhouetted against the sky and could not be counted. A roost was located on Curieuse on the first visit, but a return visit revealed only four bats, suggesting that what we had found initially was only a temporary roost.

The Table shows that the highest number of bats counted leaving the three roosts on Praslin was 1443; with the 439 counted on I.a Digue the total is 1882. This will be an underestimate and it seems that the total number of bats on Praslin and immediately adjacent islands is about 2000 . 


\section{Fruit Bat Counts on Praslin and La Digue, 1977}

\begin{tabular}{lllccc} 
Island & \multicolumn{1}{c}{ Roost } & & \multicolumn{3}{c}{ Bats counted while:- } \\
& & & Roosting & Disturbed & Dispersing \\
Praslin & \multirow{2}{*}{ I.a Pasquière } & July & 305 & 586 & 589 \\
& & August & 300 & - & 494 \\
& \multirow{3}{*}{ Fond Azore } & July & 77 & - & 469 \\
& & August & 68 & - & 719 \\
& \multirow{2}{*}{ Au Morne } & July & 64 & 132 & - \\
& & August & - & 135 & - \\
I.a Digue & & August & - & - & 439
\end{tabular}

\section{Predators}

Man is the only predator of P.s. seychellensis, and fruit bat is a traditional alternative to the staple diet of fish. In the past, bats have been shot while feeding, but after the change of government in June 1977, all guns were impounded, and netting and catapulting are now the only methods used. A catapult hanging ready for use from the veranda of a house is a common sight in the forest. Nets were also in use in Mahé and Praslin during our visits. To obtain specimens of P.s. seychellensis for our own use and to prevent pilferage of nets, we allowed small boys to operate our mist nets between trees in which bats were known to feed. Nine bats were captured, including one with wounds caused by shotgun pellets, but the bats soon learned where the nets were and avoided them.

On Praslin, a Seychellois brought us two bats he had caught; a neighbour had two caged bats awaiting consumption, and a local tour operator had a caged fruit bat as an advertisement. On Mahé, where one of the restaurants advertises bat curry, the head waiter told us that up to five bats a day were brought in by Seychellois, who were paid up to 10 rupees a bat $(13$ rupees $=£ 1)$. This outlet alone could thus account for up to 1500 bats a year. Although the Seychellois consider cooked bat a delicacy, it is chopped finely and heavily curried, and no attempt is made to remove the bones until the eating stage.

\section{Bats as Pests?}

Fruit bats feed largely on species which are of no use to the Seychellois, such as takamaka fruits Callophyllus inophyllum, kapok Ceiba pentandra and bois-beurre flowers Pentadesma butyracea, but they compete with the Seychellois for jackfruit Artocarpus heterophyllus, breadfruit A.altilis and mangoes Mangifera indica. As a result some people regard them as pests, although others consider them to be the rightful owners of unpickable fruit at the tops of trees.

\section{Conservation}

A population of 2000 bats on Praslin and the neighbouring islands gives little immediate cause for concern. It would clearly be of interest to census the numbers on Mahé, which is more populated, so that more bats may be caught, but its much greater size and steeper contours would make such a census difficult. What is alarming is the extent of predation; the Seychellois take every 
possible opportunity to procure fruit bats. It would be a great loss if this endemic mammal became as reduced in numbers as some of the endemic birds and plants, and a planned conservation policy now, regularly reviewed, might avert disaster in the future. The impounding of guns has obviously benefited the bats. Legislation to prevent trade in bats would eliminate large-scale killing for the tourist's table, and is recommended: this would still allow the people their traditional right to supplement their fish diet with any other available meat. P.s. seychellensis is not yet in need of total protection, but its status should be regularly reviewed and an attempt made to estimate the numbers on Mahé. An important factor limiting numbers is the availability of suitable roosts protected from the prevailing winds, and tree-felling should be prohibited in such areas.

\section{Acknowledgments}

Financial support for this project was provided by the Fauna Preservation Society's Oryx $100 \%$ Fund. This report could not have been produced without the assistance of Jenny Cook, Mike Cook, Ron MacDonald, Fiona Maisels, Martin Nicoll and Jimmy Suttie who spent many hours locating and counting bats.

\section{References}

1. ANON, 1977. Rodrigues Fruit Bat. Oryx 13, 5, p.432.

2. CHEKE, A.S. 1974. British Ornithologists' Union, Mascarene Islands Expedition. Report on Rodrigues (cyclostyled).

3. DURREI,I, G. 1977. The Mauritian Expedition. Jersey Wildlife Preservation Trust. Thirteenth Annual Report: 7-11.

4. HILI, J.E. 1971. The bats of Aldabra Atoll, western Indian Ocean. Phil. Trans. Roy. Soc. B. 260: 573-576.

5. KINGDON, J. 1974. East African Mammals - An Atlas of Evolution in Africa IIA: Insectivores and Bats. Academic Press. Iondon and New York.

Dr P.A. Racey, Department of Zoology, University of Aberdeen, Aberdeen AB9 2TN, UK.

\section{Captive-bred Badgers Form Wild Colony}

In 1973 two badger cubs bred at the Norfolk Wildlife Park, directed by Philip Wayre, were released on a farm in West Norfolk where a previous owner had destroyed all the badgers. The new owner, Lord Melchett, hoped to re-establish them. The badgers were released in a temporary enclosure that had been made at the foot of a bank in the middle of a wood. They soon made a burrow in the face of the bank and burrowed out of the enclosure, which was removed. In 1974 three more captive-bred cubs, a male and two females, were released at the same site, and again in 1976 two females were released. All the appearances suggested that a badger colony had become established, but success was not proved until the spring of 1979, when I ord Melchett watched a female emerge from the set, followed by three cubs. Philip Wayre believes that this is the first record of a successful reintroduction of any mustelid using captive-bred animals.

\section{The Dhole's Preferred Prey}

A study in the Nilgiri Hills of the endangered dhole, the Asiatic wild dog Cuon alpinus, about which so little is known that management plans would be difficult to draw up, suggests that sambar are preferred prey to chital, with domestic cattle rating very low. The FPS Oryx $100 \%$ Fund contributed to this study by James A. Cohen, assisted by Michael W. Fox, A.J.T. Johnsingh and Bruce D. Barnett. Their report is published in the fournal of Wildlife Management 42, 4, October 1978. 